\title{
VIABILIDADE CELULAR E ATIVIDADE ANTIFÚNGICA PROMOVIDAS POR EXTRATOS AQUOSOS DE Cucurbita реро $\mathrm{L}$
}

\section{B. SILVA ${ }^{1}$, S.D.A. SILVA ${ }^{2}$, C.M.L. de MELO ${ }^{2}$, M.C. MOURA ${ }^{3}$, L.C.B.B. COELHO ${ }^{3}$, L.E.B.VIEIRA ${ }^{1}$, K.P.RANDAU ${ }^{1}$}

${ }^{1}$ Universidade Federal de Pernambuco, Centro de Ciências da Saúde, Departamento de Ciências Farmacêuticas

${ }^{2}$ Universidade Federal de Pernambuco, Centro de Biociências, Departamento de Antibióticos

${ }^{3}$ Universidade Federal de Pernambuco, Centro de Biociências, Departamento de Bioquímica

E-mail para contato: ivanisebrito1@gmail.com

RESUMO - A resistência aos antifúngicos é um grande desafio para a clínica frente às dificuldades do tratamento das micoses. O gênero Candida apresenta as espécies Candida tropicalis, C. parapsilosis, C. glabrata, C. krusei, C. lusitaniae e C. guillermondii como os agentes mais patogênicos. Em indivíduos imunodeprimidos esses microrganismos, podem causar infecções locais ou sistêmicas. A resistência aos antifúngicos, leva a necessidade de descobertas de novas drogas, pesquisas com plantas medicinais são promissoras nesta busca. O objetivo desse estudo foi avaliar a atividade antifúngica dos extratos aquosos de folhas e sementes de Cucurbita pepo L. (abórora) e verificar a viabilidade celular de esplenócitos tratados com estes extratos. Os resultados demonstraram que os extratos aquosos tanto das folhas quanto das sementes apresentaram atividade antifúngica contra as espécies Candida albicans e C. krusei, entretanto não conseguiram inibir o crescimento das cepas Candida tropicalis e Candida parapsilosis. Quanto à viabilidade observou-se que não houve diminuição da viabilidade celular em esplenócitos em todas as concentrações testadas. Os resultados deste estudo apontam para o potencial antifúngico dos extratos.

Palavras chave: Antifúngico; Cucurbita pepo; Viabilidade celular.

ABSTRACT - Resistance to antifungals is a major challenge for the clinic in the face of difficulties in the treatment of mycoses. The genus Candida presents the species Candida tropicalis, C. parapsilosis, C. glabrata, C. krusei, C. lusitaniae and C. guillermondii as the most pathogenic agents. In immunocompromised individuals, these microorganisms can cause local or systemic infections. Resistance to antifungals leads to a need for new drug discoveries, herbal researches are promising in this quest. The objective of this study was to evaluate the antifungal activity of aqueous extracts of leaves and seeds of Cucurbita pepo L. (abóbora) and verify the cellular viability of splenocytes treated with these extracts. The results demonstrated that the aqueous 
extracts of both the leaves and the seeds presented antifungal activity against the species Candida albicans and C. krusei, however they were not able to inhibit the growth of the strains Candida tropicalis and Candida parapsilosis. Regarding the viability it was observed that there was no decrease of cell viability in splenocytes at all concentrations tested. The results of this study point to the antifungal potential of the extracts.

\section{INTRODUÇÃO}

A resistência aos antifúngicos é um grande desafio para a clínica frente às dificuldades do tratamento das micoses, sendo sugerido quando possível, o isolamento do agente infeccioso e a determinação da Concentração Mínima Inibitória (CMI) das possíveis drogas utilizadas no tratamento (COLOMBO, 2003). O gênero Candida é responsável por 2 a 3\% de todas as infecções sanguíneas, sendo locais ou sistêmicas e é representado pelas espécies patogênicas $C$. tropicalis, C. parapsilosis, C. glabrata, $C$. krusei, C. lusitaniae e C. guillermondii. Esses microrganismos, presentes em infecções de pacientes portadores de malignidades hematológicas, desenvolveram resistência aos antifúngicos através de mutações ou aumento da expressão de genes resistentes (MENEZES, et al., 2009; RIBEIRO, 2009). A diminuição da susceptibilidade destes microrganismos frente a fármacos como fluconazol, anfotericina B e flucitosina tem sido demonstrada (PAPPAS, et al., 2009).

As infecções causadas por esses patógenos em indivíduos imunodeprimidos podem ser superficiais, afetando pele e mucosas, ou invadir e disseminar-se no organismo (SPAMPINATO; DÁRIO, 2013). A candidíase orofaríngea representa a principal infecção fúngica em pacientes imunodeprimidos, causando risco de morte (BUGLI et al., 2013). O avanço da infecção por HIV pode resultar em episódios graves de candidíase. Gerando estadias prolongadas em hospitais e maiores custos do tratamento, tornando-se um problema de saúde pública (ERKOSE; ERTURAN, 2007).

Em 2002 o "Proyecto Iberoamericano de Búsqueda y Desarrollo de Antifúngicos Naturales y Análogos (PIBEAFUN)," desenvolvido na Argentina, através do Programa Iberoamericano de Ciencia Y Tecnología Para El Desarrollo (CYTE) apresentou como objetivo encontrar novos compostos antifúngicos a partir de plantas da flora latinoamericana, baseada principalmente no seu uso etnofarmacológico.

O Brasil é um país com grande biodiversidade, onde culturalmente a população faz uso de plantas medicinais para tratamento de diferentes afecções (GADELHA, et al, 2013). Cucurbita pepo L. é uma planta herbácea pertencente à família Cucurbitaceae, produz ramas rasteiras que podem chegar a $6 \mathrm{~m}$ de comprimento. Os frutos são conhecidos popularmente como abóbora, moranga ou jerimum (HEIDEN et al., 2007). A abóbora tem sido cultivada em todas as regiões brasileiras, incluindo o Nordeste (RAMOS; QUEIROZ, 2005). O uso popular, tem despertado a comunidade científica para pesquisas com a espécie, investigando seu potencial antidiabético, anti-hipertensivo, antitumoral, imunomodulação, antibacteriano, anti-hipercolesterolemico, antiparasitário e anti-inflamatório (CAILI; HUAN; QUANHONG., 2006). O objetivo deste estudo foi avaliar a atividade antifúngica promovida pelos extratos aquosos de folhas e sementes de 
Cucurbita pepo L. (abóbora) e verificar a viabilidade celular frente à esplenócitos de camundongos tratados com esses extratos.

\section{MATERIAIS E MÉTODOS}

Folhas e sementes de Cucurbita pepo L. foram utilizados para obtenção dos extratos aquosos. O material vegetal foi identificado no Instituto de Pesquisa Agroindústria (IPA- PE), onde uma exsicata foi depositada, com número de tombamento: 91093. As folhas e sementes ( 50 e $40 \mathrm{~g}$ respectivamente) foram secas em estufa a $40^{\circ} \mathrm{C}$, após essa etapa, o material foi triturado com auxílio de um liquidificador rotativo, e reduzido a pequenos fragmentos. Os extratos foram obtidos por decocção, a $100^{\circ} \mathrm{C}$ por 10 minutos, em seguida foram filtrados e armazenados em placas de Petri, para posterior liofilização por $48 \mathrm{~h}$. Após liofilização obteve-se como rendimentos 8 e $3,5 \mathrm{~g}$ respectivamente.

A atividade antifúngica foi realizada contra as cepas Candida albicans URM 5901, Candida krusei URM 6391, Candida tropicalis URM 6551, Candida parapsilosis URM 6951 utilizando faixa de concentração de $0.03 \mathrm{mg} / \mathrm{mL}$ até $2 \mathrm{mg} / \mathrm{mL}$ através de diluição seriada. A CMI das amostras foi determinada pelo ensaio de microtitulação proposto pelo Instituto de Normas Laboratoriais e Clínicas (CLSI - Clinical and Laboratory Standards, 2012). Em placas de microtitulação de 96 poços, a amostra foi adicionada ( $80 \mu \mathrm{l})$ no quarto poço a partir do qual foi diluída seriadamente em água MilliQ estéril até o décimo segundo poço da mesma fileira. Posteriormente, $40 \mu 1$ do meio caldo Sabouraud Dextrose, exceto no primeiro, que foi preenchido com $200 \mu$ do meio de cultura, correspondendo ao controle de esterilidade. O antifúngico fluconazol (64 $\mu \mathrm{g} / \mathrm{ml}$ ) foi usado como controle positivo no segundo poço. Finalmente, a suspensão fúngica $\left(80 \mu \mathrm{l} ; 10^{6} \mathrm{UFC} / \mathrm{ml}\right)$ foi acrescentada no segundo poço até o último poço da fileira. O terceiro poço (que contém microrganismos na ausência da amostra) correspondeu ao controle de crescimento de $100 \%$. As placas foram incubadas a $36^{\circ} \mathrm{C} \mathrm{e}$ a densidade óptica foi medida no tempo zero e após $24 \mathrm{~h}$ de incubação usando um leitor de microplacas. A $\mathrm{CMI}_{90}$ e a $\mathrm{CMI}_{50}$ correspondeu a menor concentração da amostra capaz de promover a redução de $\geq 90 \%$ ou $\geq 50 \%$, respectivamente, na densidade óptica, em comparação ao controle de crescimento $100 \%$.

Para a determinação da concentração mínima fungicida (CMF), alíquotas (10 $\mu \mathrm{l})$ dos poços contendo concentrações das amostras $\geq \mathrm{CMI}_{50}$ foram inoculados em placas de Petri contendo meio Sabouraud Dextrose ágar, que foram posteriormente incubados a 36 ${ }^{\circ} \mathrm{C}$ por $24 \mathrm{~h}$. A CMF corresponde a menor concentração da amostra capaz de reduzir o número de unidades formadoras de colônia (UFC) em 99,9\% em relação ao inoculo inicial. Cada ensaio foi realizado em triplicata.

O ensaio de viabilidade celular foi realizado com células de camundongos BALB machos $(\mathrm{n}=5)$, peso 45,0 $\pm 2,0 \mathrm{~g}$, obtidos a partir do biotério do laboratório de Imunopatologia Keizo Asami (LIKA) da Universidade Federal de Pernambuco (UFPE). Cada animal foi mantido em uma gaiola individual, sobcondições ambientais controladas (Ciclo luz/escuro de $12 \mathrm{~h}$, temperatura $23 \pm 2{ }^{\circ} \mathrm{C}$ e umidade $55 \pm 10 \%$ ) com água e comida 
comercial ad libitum (Labina ${ }^{\circledR}$, Agribrands of Brazil). Todos os procedimentos de animais estavam de acordo com as normas éticas dos Princípios Orientadores do Comitê de ética em Pesquisa envolvendo animais da UFPE ( $\left.n^{\circ} 0048 / 2016\right)$.

Os animais foram anestesiados usando $2 \%$ de cloridrato de xilazina (10 mg kg-1) e $10 \%$ de cloridrato de cetamina (115 mg kg-1) em injeções intramusculares. Em seguida foram eutanasiados por deslocamento cervical e o baço dos animais foi removido. A partir de cada baço foi seguido o protocolo de isolamento de esplenócitos com centrifugações seguidas usando-se Ficoll (Ficoll-PaqueTM PLUS) e PBS 1X.

Os esplenócitos de camundongos $\left(2 \times 10^{4}\right.$ células/poço) foram cultivadas em microplacas estéreis de 96 poços pretas (Greiner Bio-one) em RPMI 1640 suplementados com $10 \%$ de soro bovino fetal e $50 \mu \mathrm{g} / \mathrm{mL}$ de gentamicina. Cada extrato foi avaliado em cinco concentrações $(6 ; 12 ; 25 ; 50$ e $100 \mu \mathrm{g} / \mathrm{mL})$ em triplicata. As células foram incubadas durante 24 horas a $37^{\circ} \mathrm{C}$ e $5 \%$ de $\mathrm{CO}_{2}$ com os extratos. Um controle positivo (células incubadas com meio RPMI) foi utilizado neste ensaio. Após 24h, foi realizado o ensaio de viabilidade e citotoxicidade utilizando-se o kit ApoTox-Glo ${ }^{\text {TM }}$ (Promega ${ }^{\circledR}$ ), seguindo as orientações do fabricante. A leitura da placa foi feita pelo GloMax ${ }^{\circledR}$ Explorer System, os dados foram avaliados no Excel $^{\circledR} 2007$ e expressos em média e desvio padrão.

\section{RESULTADOS E DISCUSSÃO}

\subsection{Atividade Antifúngica}

Os extrato de folhas e sementes de Cucurbita pepo L. apresentaram CMI de 0,03 $\mathrm{mg}$ para Candida albicans. A cepa Candida krusei, apresentou CMI (50 e 90) 0,5 e 1 g/mL para o extrato aquoso de folhas e $\mathrm{CMI}_{(50 \text { e } 90)} 0,25$ e $1 \mathrm{mg} / \mathrm{mL}$ para o extrato de semente. Os extratos não conseguiram inibir o crescimento das cepas Candida tropicalis e Candida parapsilosis (Tabela 1).

Tabela 1: Atividade antifúngica promovida pelos extratos aquosos de folhas e sementes de Cucurbita pepo L. em espécies de Candida

\begin{tabular}{|c|c|c|c|c|}
\hline \multirow[t]{2}{*}{ Espécie } & \multicolumn{2}{|c|}{$\begin{array}{c}\text { Cucurbita pepo } \\
\text { (folha) }\end{array}$} & \multicolumn{2}{|c|}{$\begin{array}{c}\text { Cucurbita pepo } \\
\text { (semente) }\end{array}$} \\
\hline & CMI & $\mathrm{CMF}$ & CMI & $\mathrm{CMF}$ \\
\hline Candida albicans & 0,03 & AND & 0,03 & AND \\
\hline Candida krusei & $\begin{array}{l}\mathrm{CMI}_{90}: 1 \\
\mathrm{CMI}_{50}: 0,5\end{array}$ & AND & $\begin{array}{l}\mathrm{CMI}_{90}: 1 \\
\mathrm{CMI}_{50}: 0,25\end{array}$ & AND \\
\hline Candida tropicalis & AND & - & AND & - \\
\hline Candida parapsilosis & AND & - & AND & - \\
\hline
\end{tabular}

AND: Atividade não detectada; concentração mínima inibitória - (CMI); concentração mínima fungicida - (CMF) expressos em $\mathrm{mg} / \mathrm{mL}$. 
Cucurbita pepo L. é usada popularmente em países como China, Argentina, Índia, México e Brasil para tratamento de diabetes e parasitoses, além de ser utilizada para alimentação. O uso popular tem despertado a comunidade científica para pesquisas com a espécie, investigando seu potencial antidiabético, anti-hipertensivo, antitumoral, imunomodulador, antibacteriano, anti-hipercolesterolemico, antiparasitário e antiinflamatório. Todas as partes da planta são usadas na medicina popular, as folhas pisadas são usadas externamente para queimaduras e erisipela. (LORENZI, et al., 2015). As sementes são consideradas vermífugas e o chá das flores é antitérmico (CAILI et al., 2006). Estudo realizado com óleo de C. pepo mostrou atividade antifúngica contra C. albicans (HAMMER; CARSON; RILEY, 1999). O extrato aquoso dos frutos da espécie apresentou atividade contra bactéria Escherichia coli e Pseudomonas aeruginosa (KAMALI; MAHJOUB, 2009).

\subsection{Viabilidade celular}

A avaliação da viabilidade celular frente aos extratos em diferentes concentrações (6, $12,25,50$ e $100 \mu \mathrm{g}$ ) revelou que os extratos não diminuíram a viabilidade celular. Foi possível observar que as células permaneceram viáveis, mesmo nas maiores concentrações, quando comparadas com o controle (Figura 2A e B).

Figura 2: Esplenócitos de camundongo tratados com diferentes concentrações de Cucurbita pepo L. em 24 horas de ensaio. A - Ação promovida pelo extrato aquoso das folhas B - Ação promovida pelo extrato aquoso das sementes
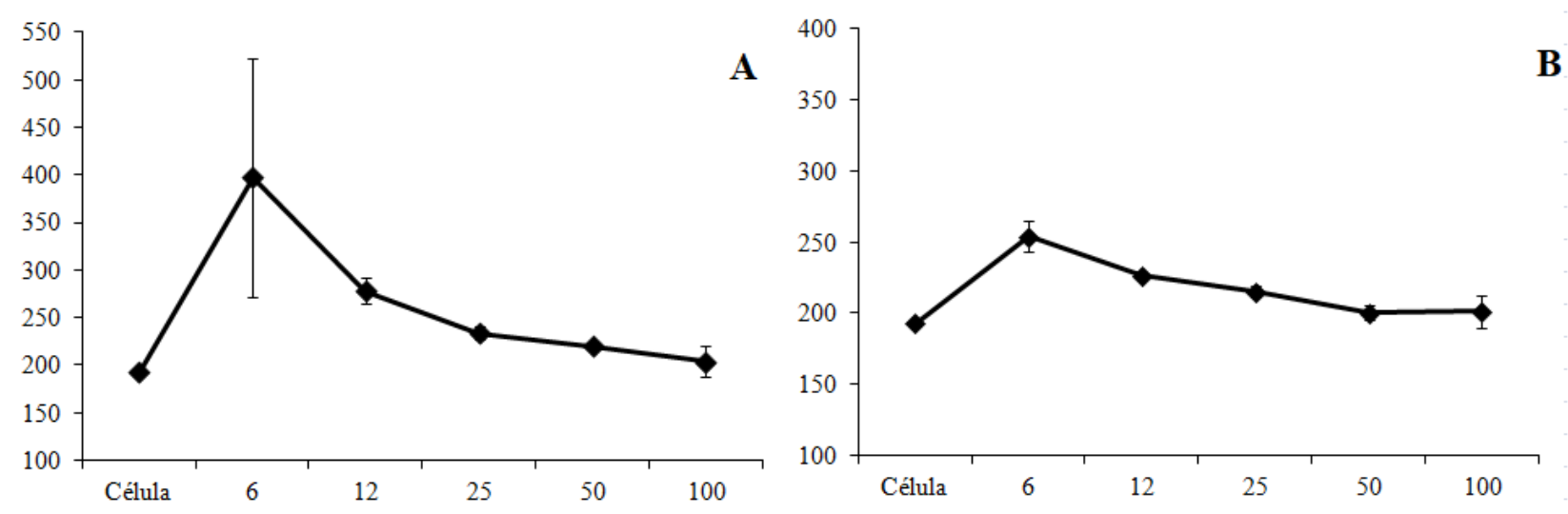

Os resultados apontam para o perfil não tóxico promovido por ambos os extratos. Este estudo corrobora com os resultados encontrados por Shokrzadeh e colaboradores (2010), que avaliaram a citotoxicidade do extrato hidroalcoólico de folhas de $C$. pepo sobre as linhagens tumorais HepG2 e CT26 e linhagens normais de fibroblastos e células de ovário de hamster $(\mathrm{CHO})$, onde observaram uma $\mathrm{IC}_{50}$ de 132.6 \pm 4.3 e $167.2 \pm 6.3 \mathrm{~m} \mu / \mathrm{mL}$ para as células tumorais, e $239.2 \pm 10.3$ e $241.4 \pm 9.6 \mathrm{~m} \mu / \mathrm{mL}$ para as linhagens normais (SHOKRZADEH, et al., 2010). Nesse caso, percebe-se que os extratos não apresentam toxicidade para células normais. 


\section{CONCLUSÃO}

Os extratos aquosos de folhas e sementes de Curcubita pepo L apresentaram atividade antifúngica contra as cepas Candida albicans e C. krusei em baixas concentrações. Além disso, os extratos não apresentaram diminuição da viabilidade celular nas concentrações testadas frente à esplenócitos de camundongos, demonstrando seu uso seguro para futuros ensaios. Estudos estão em desenvolvimento para a investigação do potencial desses extratos frente às células imunológicas no que se refere à sua capacidade de imunomodulação.

\section{REFERÊNCIAS}

BUGLI, F.; CACACI, M.C.; MARTINI, C.; TORELLI, R.; POSTERARO, B.; SANGUINETTI, M.; STERBINI , F.P. Human Monoclonal Antibody-Based Therapy in the Treatment of Invasive Candidiasis. Clinical and Developmental Immunology.v.2013, p. 1-9, 2013.

CAILI, F.; HUAN, S.; QUANHONG, L. A Review on Pharmacological Activities and Utilization Technologies of Pumpkin. Plant Foods for Human Nutrition, v. 61, n. 2, p. 70-77, 7 jun. 2006.

CLSI. 2012. Reference method for broth dilution antifungal susceptibility testing of yeasts, 3rd ed. M27-A3. Clinical and Laboratory Standards Institute, Wayne, PA.

COLOMBO, A.L.; GUIMARÃES, T.; Epidemiologia das infecções hematogênicas por Candida spp. Revista Sociedade Brasileira Medicina Tropical Uberaba, v.36, n.5, 2003.

ERKOSE, G.; ERTURAN, Z. Oral Candida colonization of human immunodeficiency virus infected subjects in Turkey and its relation with viral load and CD4+ T-lymphocyte count. Mycoses. v.50. p.485-90, 2007.

GADELHA, C.L.; JUNIOR, V.M.P.; BEZERRA, K.K.S.; PEREIRA, B.B.M.; MARACAJÁ, P.B. Estudo bibliográfico sobre o uso das plantas medicinais e fitoterápicos no Brasil. Revista Verde. v. 8, n. 5, p. 208 - 21, 2013.

HEIDEN, G.; BARBIERI, R. L.; NEITZKE, R. S. Chave para a identificação das espécies de abóboras (Cucurbita, Cucurbitaceae) cultivadas no Brasil. Pelotas: Embrapa Clima Temperado, 2007.

LORENZI, H.; LACERDA, M. T. C.; BACHER, L. B. 2015. Frutas no Brasil: nativas e exóticas (de consumo in natura). Instituto Plantarum de Estudos da Flora, São Paulo

MENEZES, E.A.; MENDES, L.G.; CUNHA, F.A. Resistência a antifúngicos de Candida tropicalis isoladas no Estado do Ceará. Revista da Sociedade Brasileira de Medicina Tropical. v. 42, n.3, p. 354-355, 2009.

PAPPAS, P.G ; KAUFFMAN, C.A.; ANDES, D.; BENJAMIN, D.K.; Jr, CALANDRA T.F.; EDWARDS J.E.; JR, FILLER S.G.; FISHER J.F.; KULLBERG B.J.; OSTROSKY, Z.L.;REBOLI, A.C; REX J.H.;WALSH T.J.; SOBEL J.D. Clinical Practice Guidelines for the Management of Candidiasis: 2009 Update by the Infectious Diseases Society of America. Clinical Infectious Diseases. v. 48, p. 503-35, 2009.

RAMOS S.R.R.; QUEIROZ, M.A.. Recursos genéticos de abóbora no Nordeste brasileiro. In: LIMA CLM. Recursos genéticos de hortaliças: riquezas naturais. São Luís: Instituto Interamericano de Cooperação para a Agricultura, 99-116. 2005 
RIBEIRO, P.M.; ITO C.Y.K.; JUNQUEIRA, J.C.; JORGE, A.O.C. Isolamento de Candida spp. com utilização de meio de cultura cromogênico CHRO Magar Candida. Brazilian Dental Science. v.12, n.4, p.40-45. 2009.

SHOKRZADEH, M.; AZADBAKHT, M.; AHANGAR, N.; HASHEMI, A.; SAEEDI SARAVI, S. S. Cytotoxicity of hydro-alcoholic extracts of Cucurbita pepo and Solanum nigrum on HepG2 and CT26 cancer cell lines. Pharmacognosy Magazine, 6, 176-179. 2010.

SPAMPINATO, C.; DARÍO, L. Candida Infections, Causes, Targets, and Resistance Mechanisms: Traditional and Alternative Antifungal Agents. BioMed Research International. v. 2013, p. 1-13, 2013.

\section{AGRADECIMENTOS}

Os autores agradecem a Coordenação de Aperfeiçoamento de Pessoal de Nível Superior (CAPES) pelo apoio financeiro, ao Laboratório de Pesquisas Moleculares e Experimentais, ao Laboratório de Bioquímica de Proteínas e ao Laboratório de Atividades Imunológicas e Antitumorais pelo suporte no desenvolvimento dos experimentos. Agradecemos ainda à, ao Laboratório de Farmacognosia situado no Departamento de Ciências Farmacêuticas-UFPE por proporcionar condições para desenvolvimento da pesquisa. 